\title{
UNICEF Helps Rehabilitate Physically Handicapped Children in Ten Countries
}

\author{
UNICEF Public Information Division United Nations New York
}

Six months ago a paralytic disease of unknown origin suddenly broke out in the Moroccan town of Meknes and the surrounding areas, causing paralysis to some 200-300 persons a day. By the time the cause was established by the World Health Organisation neurologists and drastic governmental measures were taken to prevent further spread of the disease, the total number of victims had reached about 10,000 of whom more than half were children and adolescents.

The cause was found to be poisoning by ortho-cresylphosphate, a compound present in a lubricant used by United States Air Force planes. Some Moroccan merchants had used the lubricant to dilute olive oil used for cooking.

Becausi of the complete lack of trained physiotherapists in the country and the immediate need for therapeutic equipment, the Moroccan government applied to the United Nations Children's Fund, UNICEF, the World Health Organisation, The League of the Red Cross Societies and other international organisations for assistance.

On receiving the technical approval of WHO, UNICEF allocated $\$ 42,000$ for the provision of ward equipment (wheel chairs, auto-claves and treatment tables) to two emergency hospitals at Meknes and Kenitra. The equipment weighing about 17 tors, was shipped to Morocco during February.

In addition to emergency situations like the Moroccan one, UNICEF has adopted, ever since its inception, a policy of aiding governments to establish or strengthen programmes for the treatment and rehabilitation of physically handicapped children by providing essential equipment and supplies. The aid is given primarily to model and pilot centres for demonstration and training in modern rehabilitation techniques. These centres provide the nuclei for the development of national rehabilitation programmes.

Currently there are ten countries receiving UNICEF aid in their projects for the rehabilitation of handicapped zhildren. These are: Greece, India. Indonesia, Japan. Pakistan, Poland, Spain, Thailand and Yugoslavia.

Among the rehabilitation programmes presently being zonducted with aid from UNICEF is a project in Greece. This country has received a UNICEF allocation of $\$ 76,100$ to provide supplies and equipment for three hospitals. two children's clinics and the National Rehabilitation Centre for Physically Handicapped Children at Voula which serves as a national training and demonstrating centre. This centre is equipped to handle 300 children. Equipment for an orthopaedic workshop at Voula was also provided by the Fund. The Orthopaedic Surgery Hospital at Pendeli which was opened in 1957 with 240 beds was also provided with equipment by UNICEF. With UNICEF and World Health Organization assistance a school of Physical Therapy was opened and held its first courses in 1957/58. A major step in the direction of developing a national programme for care of handicapped children was taken by the Greek government itself when it set up the National Rehabilitation Board.

Japan which has very advanced services for the rehabilitation of handicapped children, received from UNICEF. under an allocation of $\$ 77,800$. equipment for its National Centre in Tokyo, which gives guidance and advice to the provinces in the rehabilitation of handicapped children. UNICEF has also provided equipment for 48 prefectural hospitals patterned on the national centre.
India, through a small UNICEF allocation, has received equipment for a workshop for the manufacture of prosthetic applicances in the Bombay Centre for the treatment and rehabilitation of physically handicapped children. The centre is being up-graded as a national institution to train personnel for such services throughout India.

Thanks to the efforts of The Indonesian Institute for The Care of Crippled Children, a phenomenal change in the attitude toward the handicapped has taken place in that country during the last decade. The traditional feeling of shame that once made Indonesian parents hide their crippled children, is dying out rapidly. UNICEF has allocated $\$ 30,000$ for equipment for the five centres

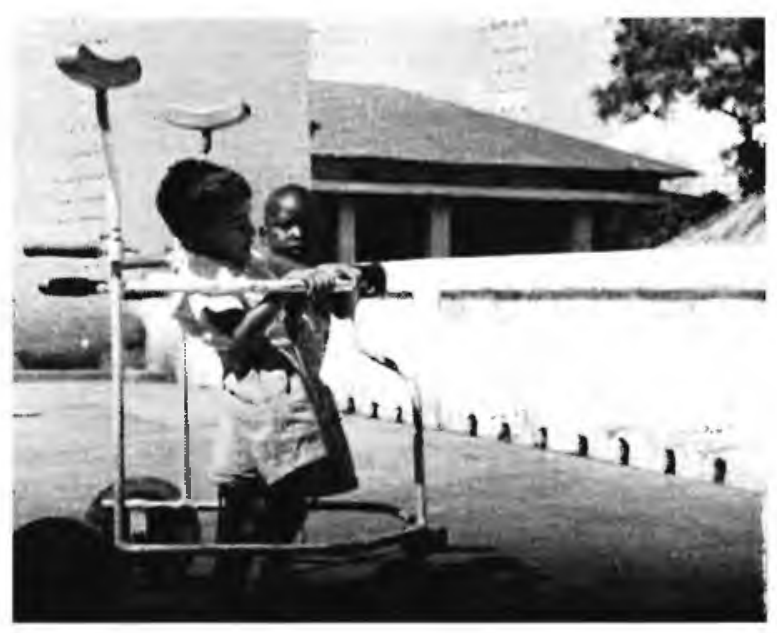

PRACTICE WILL PAY.

ICEF 2895.-Two youngsters at the Mulago Hospital in Kampala, Uganda, learn to strengthen muscles wasted by polio through outdoor exercise. Helping the government improve medical services for children, the United Nations Children's Fund (UNICEF) has provided clinic equipment, vehicles and other supplies for this and other hospitals and health centres throughout the country. The World Health Organization lends technical guidance. UNICEF Photograph.

that were established to treat Indonesian handicapped children. It has also provided teaching aids for two major centres training assistant physical therapists who after finishing their training serve in the smaller centres

Four years ago UNICEF allocated $\$ 45,500$ to Spain to provide physical, occupational, and speech therapy equipment for a national progranme for the rehabilitation of handicaped children. UNICEF help went to seven demonstration and training centres (four in Madrid, one each in Barcelona, Santander and Valencia). The "rehabilitation teams" which were trained in these centres included medical, social, educational and vocational personnel. The United Nations and the World Health Organization are providing experts and fellowships in physical and occupational therapy. UNICEF equipment 
has been installed at the Clinica de la Concepcion which is Madrid's No. 1 training centre, and at the Provincial and Nino Jesus hospitals in Madrid.

Although prior to 1951 UNICEF had given aid on a rather small scale to Yugoslav orthopaedic clinics of the children's hospitals at Belgrade, Ljubljana and Zagreb and to schools for the blind and deaf at Zagreb and Zemun, it was in 1957 that UNICEF substantially increased its aid for the rehabilitation of handicapped Yugoslav children. For a co-ordinated national programme, more than $\$ 100,000$ was approved for the strengthening of six institutions to train physiotherapists, vocational counsellors and specialized teachers for the rehabilitation of children with orthopaedic or sensorial handicaps. UNICEF has provided equipment for physiotherapy, for diagnosis and testing, for training of the blind, for audiological therapy and for vocational training.

A course specializing in physical medicine and rehabilitations has been introduced at three Universities in Yugoslavia. A Federal Rehabilitation Board has been established comprising representatives of all the rehabilitation centres. The Belgrade Centre has become the Federal Rehabilitation Institute where first-rate research work is being carried out in the methods of rehabilitation of children with hearing and speech defects.

Early in 1956 the new Lebanese national rehabilitation centre was inaugurated at Hazemieh near Beirut. This is the first centre of $i t s$ kind in the Arab countries, and is now serving as a model demonstration and training centre for the care of handicapped children of many of the Eastern Mediterranean countries. Physio and hydrotherapy are provided. There is also a department for occupational therapy and a prosthetics workshop.

This project was started with assistance from the Lebanese Union for Child Care, the American University of Beirut and the French Faculty of Medicine.

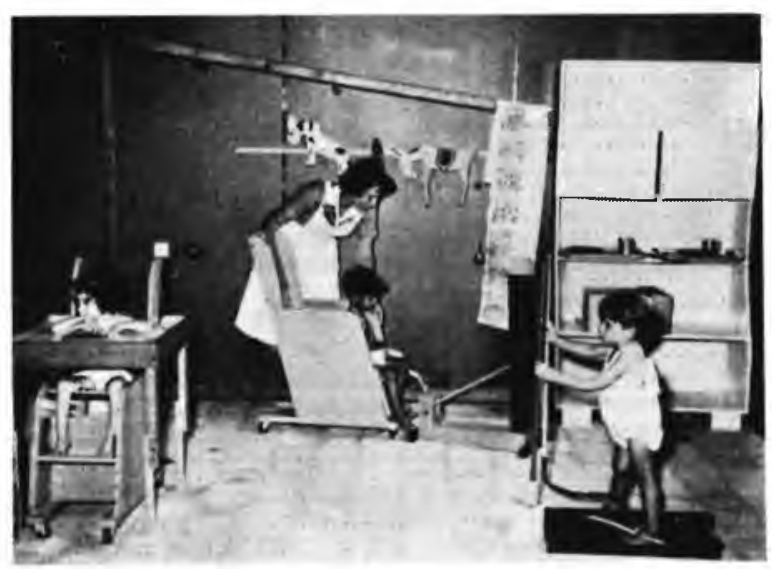

Learning all over again-after Polio

ICEF 1570-At Sarafand General Hospital, near Tel Aviv, Israel, youngsters work to regain the use of polio-crippled limbs. Supervising is a young trainee-therapist. The aftermath of severe polio epidemics, a disease that knows no national boundaries, has left Israel with large numbers of children in need of rehabilitation care.

UNICEF-which responded to Israel"s polio crisis in 1950 by contributing iron lungs-is now providing rehabilitation equipment for a polio wing at Sarafand General Hospital, near Tel Aviv, which Israel is expanding as a national rehabilitation centre. In addition to treatment facilities, Sarafand will have a school of physiotherapy, vocational training and a welfare section.

Since 1948, when Israel was established as a State, UNICEF has helped with early short-term supplies for feeding, clothing and an anti-tuberculosis campaign; and in recent years with equipment for mother-child health services and the development of local milk supplies. Israel matches the value of all UNICEF aid locally.

$$
\text { End of caption. }
$$

Because rehabilitation programmes are relatively costly in relation to the number of children helped, they have a somewhat lower priority in UNICEF's aid programmes, as compared for instance to maternal and child welfare services and eradication of mass diseases.

UNICEF is not satisfied merely to help governments meet immediate needs of children. It chooses to help projects which provide a sound basis for comprehensive and continuous services to improve child health and welfare.

In contrast to the limited aid given by UNICEF to projects for rehabilitation of physically handicapped children, UNICEF aid in general helped last year in one way or another some 55 million children and mothers in 104 different countries and territories. The Fund has given equipment and supplies to more than 7,000 rural health centres and 15,000 village sub-centres. In 1959 UNICEF aid allocations totalled $\$ 24$ million to be spent. on the same projects. However, considering the enormity of the task of helping the children in the under-developed areas of the world, the present effort and expenditure has still a long way to go before the vicious circle of disease, hunger and ignorance is broken.

This sad situation admittedly is ages old but the way to overcome it is new and the desire to overcome it is for the first time in mankind's history, universal. Considering the present pace and intensity of effort public health experts fear it may take many a generation to defeat hunger and disease and in the course of it all many a generation might have to be sacrificed-unless a short-cut is found for this salvaging process. One short-cut is to double the effort, on both national and international levels, by the more fortunate peoples who can afford greater efforts in this direction.

\section{W. C. P. T.}

(Coninued from opp. page).

\section{Fourth International Congress}

\section{Copenhagen Congress, 1963}

The Fourth International Congress of the W.C.P.T. will be held in Copenhagen from Monday, June 17th to Saturday, June 22nd, 1963.

\section{W.C.P.T. Annual Report}

\section{Excerpts:}

Miss G. V. M. Griffin (Great Britain) who had devoled so much of her time and energy to the affairs of the World Confederation during her three years Presidency retired from office and was succeeded by Mrs. Rudie Agersnap (Denmark) who is well known to many physiotherapists for her devoted work for the World Confederation since its foundation.

Two other members retired from the Executive Committee Miss M. Elson (U.S.A.) and Miss M. D. Verco (Australia) and they were replaced by LI. Col. A. P. Snyder (U.S.A.) and Miss M. Mack (Australia).

A new project already being tackled by Miss Elson (U.S.A.) and Miss Gower-Rees (Canada) is the drafting of guidance material on equipment.

The names of physical therapists suitable for pioneer projects were sent to World Health Organisations and World Veteran Federation, and in the closing days of 1959 physical therapists from 7 or 8 member-organisations answered the call of W.H.O. and the International League of Red Cross Societies to fly immediately to Morocco to treat 10,000 patients suffering from paralysis. 